7 Peritz, E., Annals of Human Genetics, 1971, 34, 389.

McNeil, C., Warenski, L. C., Fullmer, C. D., and Trentelman, E. F. American fournal of Clinical Pathology, 1954, 24, 767.

- Takano, K., and Miller, J. R., Fournal of Medical Genetics, 1972, 9, 144 10 Holborow, E. J., et al., British fournal of Experimental Pathology, 1960, 41, 430.

1 Coombs, R. R. A., and Dodd, B., Medicine, Science, and the Law, 1961, 1, 359.

12 Krieg, H., and Kasper, K., German Medical Monthly, 1968, 13, 171.

13 Clarke, C. A., et al., Lancet, 1970, 1, 793.

14 Behrman, S. J., Buettner-Janusch, J., Heglar, R., Gershowitz, H., and Tew, W. L., American fournal of Obstetrics and Gynecology, 1960, 79, 847 .

\section{A Common Goal?}

Like the hero-or villain-in the old-fashioned silent movie serials the General Medical Council crisis regularly teeters at the edge of the cliff but never quite falls off. So it was in the latest episode when the B.M.A. Council met specially last week (Supplement, p. 29) to discuss the report of the Joint B.M.A./G.M.C. Working Party on the G.M.C.'s functions (Supplement, p. 33). Two facets of the G.M.C., its constitution ${ }^{1}$ and its finance, ${ }^{2}$ have already been studied and the results broadly accepted by the profession. The latest study, a working party set up in July and chaired by Sir Ronald Tunbridge, has been seeing whether the differences between the G.M.C. and the B.M.A. about the former's functions are narrow enough to be resolved within the profession.

According to the report differences exist but the working party saw them as "capable of resolution by further detailed discussions." Its members had faced a tight timetable as the Representative Body in approving the study in July had set a deadline of six months for an agreed report. ${ }^{3}$ Sir Ronald Tunbridge explained to the Council that while the discussions ranged over many subjects (listed in appendix $\mathbf{C}$ of the report) he and his colleagues had dealt in principle with certain broad areas. These were registration; the preregistration year; registration of overseas doctors; specialist registration; the cost of registration; undergraduate medical education; professional discipline; and communication with the profession. Though described by one Council member as "talk about talks," the report has served a useful function in clearing the decks for more detailed discussions. By a large majority the Council decided that progress so far justified a move forward to such discussions. This decision was helped, no doubt, by the news from Mr. Walpole Lewin that he expected no erasures from the Register until December-several weeks later than the Council had thought likely at its last meeting. 4

This extra breathing space should help, though the B.M.A. Council will make a final decision on whether it thinks the R.B.'s conditions have been met on 22 November, when it will have the reaction of the full G.M.C. (meeting on 9 November) to the joint report. If the G.M.C. reacts unfavourably or is thought to be procrastinating then the B.M.A. is likely to endorse the call for a public inquiry made in October by some members of Council. Other medical bodies have already publicly called for such an inquiry but Sir Keith Joseph, dealing recently with a Parliamentary question asking whether he would hold a Government inquiry into the G.M.C., showed that he was awaiting the outcome of the joint discussions before deciding "what further action, if any, is required concerning doctors threatened with removal ...."
The Chairman of Council reported that forecasts of thousands of doctors being struck off for non-payment of the annual retention fee were ill founded. At the worst he expected that only a handful of doctors would be removed from the Register in December if they persisted in refusing to pay a fee. The Council was nevertheless concerned about the possibility of erasures, and most doctors would think that any such action by the G.M.C. at this stage would be untimely. However, as more than one speaker pointed out, B.M.A. policy is to advise doctors to pay a fee on a year-to-year basis while discussions continue. Should the present talks break down a new situation will arise, but if they prosper and an agreed report is presented to the A.R.M. at Folkestone next June then the Representative Body can decide on future action.

The report shows that the G.M.C. and the profession's chief representative organization have a common goal in wanting a statutory professional body to control basic medical education, registration, and discipline. Disagreements about how best to reach this goal have been a major factor in the present messy crisis, with doctors publicly divided on what to do, and all parties contributing to the haphazard course of events. In retrospect an intraprofessional inquiry dealing with the functions, structure, and finance in that order should have been launched when the lack of confidence among many doctors in the G.M.C.'s activities became clear. But politics are rarely logical and given that the two major parties now seem to be pointing roughly in the same direction, the profession can reasonably be asked to allow a few more months before passing final judgement. The arrival of any martyrs on the scene at this stage will do little to achieve a wise and generally acceptable solution. Furthermore, premature martyrdom will probably attract little support among doctors and less among the public, who may soon get impatient with a squabble they cannot understand and call for the Government to step in and sort out the confusion. The end result might not then be to doctors' liking.

\footnotetext{
1 British Medical fournal Supplement, 1971, 1, 55.

3 British Medical fournal, 1972, 3, 253.

British Medical fournal Supplement, 1972, 4, 3.
}

\section{Mixed Connective Tissue Disease}

Some patients with a rheumatic type of disease show such a diversity of symptoms and signs as to defy precise rheumatological diagnosis. ${ }^{1-3}$ Commonest among these mixed syndromes are ones with features of rheumatoid arthritis associated with those of systemic lupus erythematosus and syndromes with systemic sclerosis complicated by features of either dermatomyositis or systemic lupus. Despite initial diagnostic difficulties the patient's subsequent history usually permits a satisfactory resolution of the diagnostic problem. But some of the mixed syndromes do seem to persist indefinitely, and now a combined study from the U.S.A. has defined the features of what appears to be a distinct disease which the authors designate "mixed connective tissue disease."4

Over the past eight years G. C. Sharp and colleagues have studied 25 patients in this category. The clinical features indicated mixed connective-tissue lesions. Thus 
24 of the patients had arthralgia and arthritis, 22 swelling of the hands and fingers, many with skin changes of scleroderma, 21 Raynaud's disease, 18 myositis, 17 lymphadenopathy, and 20 hypergammaglobulinaemia. Several had skin rashes typical of dermatomyositis, and of the 22 patients on whom cine-oesophograms were performed 17 showed abnormal motility such as found in scleroderma. Histopathology entirely confirmed these clinical findings. Thus six out of 10 skin biopsies were characteristic of scleroderma and seven out of eight muscle biopsies showed inflammatory infiltrates, so confirming the presence of myositis already indicated by typical electromyograms and raised levels of creatine phosphokinase. Only four patients had an erythematous rash similar to that of systemic lupus, and, of especial significance, only one patient developed a renal lesion of indeterminate nature despite the length of followup, which ranged from 8 weeks to 8 years.

In support of the hypothesis that mixed connective tissue disease is an entity distinct from the hitherto recognized diseases of the connective tissues is the presence in all 25 patients of an antibody to an extractable nuclear antigen, which in its purest form so far obtained is an RNA protein of molecular weight greater than 20,000 . The specific antibody is readily detected by tanned cell agglutination, and in these patients it was detected at dilutions between 1 in 1,000 and 1 in $1,000,000$. The only other conditions in which a similar antibody was found was systemic lupus erythematosus, but that antibody could be readily distinguished from the one in mixed connective tissue disease because of its much lower titre and because the agglutination of the coated cells was resistant to the action of RNAse.

The response of these patients to high doses of prednisone, $1 \mathrm{mg} / \mathrm{kg}$ body weight daily, was usually good, and the majority required little or no maintenance therapy. Even the sclerodermatous changes, in contrast to classical scleroderma, responded in a satisfactory manner.

Should mixed connective tissue disease be regarded as distinct from the other recognized diseases of the connective tissues? Since it can be differentiated from them on both clinical and serological grounds, and since it carries a more benign prognosis, with clear-cut therapeutic requirements, the differentiation would appear to worth making.

1 Dubois, E. L., Chandor, S., Friou, G. J., and Bishel, M., Medicine, 1971, 50, 199.

2 D'Angelo, W. A., Fries, J. F., Masi, A. T., and Shulman, L. E., American Fournal of Medicine, 1969, 46, 428.

Tuffanelli, D. L., and Winkelmann, R. K., Archives of Dermatology, 1961, 84, 359 .

- Sharp, G. C., Irvin, W. S., Tan, E. M., Gould, R. G., and Holman, H. R., American Fournal of Medicine, 1972, 52, 148.

\section{Renal Radiology}

Recent advances in the treatment of renal disease have been accompanied by equally impressive progress in the histopathology, immunology, bacteriology, and physiology of the kidney. Radiology has not lagged behind. Originally the intravenous pyelogram, as its name implies, was used mainly to examine the kidney's drainage system, but now as much attention is paid to the nephrogram, and it would be more correct to refer to it as an intravenous urogram. Furthermore, radiology no longer provides only a static picture of renal structure; it has become an important tool in the dynamic study of functional disturbance in disease. The current edition of the British Medical Bulletin, which is devoted to renal radiology, provides a timely review of the clinical status and potential for research in the field.

Undoubtedly the most important practical innovation has been the recognition that the use of high dosage of the contrast media enables a useful urogram to be obtained in patients with severe renal failure. Since obstruction of the urinary tract can often be excluded by this means, the need for the more difficult and hazardous retrograde pyelography has been lessened. The excretory urogram is of value even in the differential diagnosis of oliguric acute renal failure. For example, acute tubular necrosis characteristically produces an immediate, dense, and persistent nephrogram with little or no pyelogram, an appearance which has been observed in only one other condition-acute suppurative pyelonephritis. In addition this observation has helped our understanding of the pathogenesis of acute tubular necrosis, since it supports the theory of continuing glomerular filtration with almost complete reabsorption of tubular fluid. I. K. Fry and W. R. Cattell have been pioneers in the dynamic interpretation of the excretory urogram, and in the British Medical Bulletin they analyse in detail the nephrographic pattern in various disorders. The safety of the contrast media is fundamental to their use in high dosage, and from a comprehensive account of their toxicity by R. G. Grainger it is reassuring to learn that with simple precautions, especially against dehydration, the present-day agents are remarkably safe.

Arteriography is a well-established technique for the investigation of the major renal vessels and of renal tumours and cysts, but little attention has been paid to the smaller vessels. Macro-angiography, however, enables vessels as small as the interlobular arteries to be visualized, and $\mathbf{M}$. E. Sidaway describes characteristic patterns in diseases such as hypertension, chronic pyelonephritis, and polyarteritis nodosa. J. P. Lavender and T. Sherwood give other examples of the use of radiology in pathophysiological research with their studies of the renal microcirculation in experimental haemorrhagic hypertension in the dog. Bone disease in uraemia, formerly little more than a pathological curiosity, has increased in importance with the advent of long-term haemodialysis, for it has crippled many otherwise rehabilitated patients. Separation of the various radiological patterns is necessary for the rational choice of treatment, and these are detailed, together with a correlation with bone histology, by F. H. Doyle and his colleagues.

Other articles deal with the techniques of videocystography, topographical scintigraphy, and ultrasonic and isotopic diagnostic methods. Any clinician or radiologist with a special interest in renal diseases will find this issue of the Bulletin a useful progress report in a rapidly advancing field.

1 British Medical Bulletin, 1972, 28, No.3.

\section{Pertussis in Adults}

If a doctor has spent a large part of his life working in the whooping-cough wards of an infectious diseases hospital, he will probably have seen a few cases of whooping-cough in adults. No doctor will have seen many, for whooping-cough is a disease of early childhood. But no age group is immune..$^{1-3}$ Second attacks may occur, though very rarely. ${ }^{34}$ And immunization does not confer life-long immunity. 5

An attack in the adult may be typical or atypical. In the 